AperTO - Archivio Istituzionale Open Access dell'Università di Torino

Bringing Objectification into Social Relationships Research: Is Self-Objectification Harmful for Authenticity?

This is a pre print version of the following article:

Original Citation:

Availability:

This version is available http://hdl.handle.net/2318/1657872

since 2020-04-02T17:59:40Z

Published version:

DOI:10.1017/sjp.2016.34

Terms of use:

Open Access

Anyone can freely access the full text of works made available as "Open Access". Works made available under a Creative Commons license can be used according to the terms and conditions of said license. Use of all other works requires consent of the right holder (author or publisher) if not exempted from copyright protection by the applicable law. 


\section{The Spanish Journal of Psychology}

Date of delivery: 13-05-2016

Journal and vol/article ref: $\quad$ sjp $\quad$ S1138741616000342

Number of pages (not including this page): 7

This proof is sent to you on behalf of Cambridge University Press. Please print out the file and check the proofs carefully. Please ensure you answer all queries.

Please EMAIL your corrections within

2 days of receipt to:

\section{Ana Montero \\ <psyjourmanaging@psi.ucm.es>}

Please download the relevant copyright transfer form below and return to

journalscopyright@cambridge.org

Standard Copyright Form: http://journals.cambridge.org/images/fileUpload/documents/SJP_ctf.pdf

Open Access Copyright Form: http://journals.cambridge.org/images/fileUpload/documents/SJP_ctf_oa.pdf

Authors are strongly advised to read these proofs thoroughly because any errors missed may appear in the final published paper. This will be your ONLY chance to correct your proof. Once published, either online or in print, no further changes can be made.

NOTE: If you have no corrections to make, please also email to authorise publication.

- The proof is sent to you for correction of typographical errors only. Revision of the substance of the text is not permitted, unless discussed with the editor of the journal. Only one set of corrections are permitted.

- Please answer carefully any author queries.

- Corrections which do NOT follow journal style will not be accepted.

- A new copy of a figure must be provided if correction of anything other than a typographical error introduced by the typesetter is required.

- If you have problems with the file please email psyjourmanaging@psi.ucm.es

Please note that this pdf is for proof checking purposes only. It should not be distributed to third parties and may not represent the final published version.

Important: you must return any forms included with your proof. We cannot publish your article if you have not returned your signed copyright form

\section{Please do not reply to this email}

NOTE - for further information about Journals Production please consult our FAQs at http://journals.cambridge.org/production_faqs 


\section{Author Queries}

QA $\quad$ The distinction between surnames can be ambiguous, therefore to ensure accurate tagging for indexing purposes online (eg for PubMed entries), please check that the highlighted surnames have been correctly identified, that all names are in the correct order and spelt correctly. 


\title{
Bringing Objectification into Social Relationships Research: Is Self-Objectification Harmful for Authenticity?
}

\section{QA Chiara Rollero}

University eCampus (Italy)

\begin{abstract}
Self-objectification is a pervasive process in contemporary Western societies and psychological literature has largely shown its negative consequences in terms of body shame, appearance anxiety, mental health and performance. Mass media play a key role in promoting such process through the extensive sexualization of individuals' body and the separation of sexualized body parts from the rest of the body. The purpose of the present study was to extend past research by examining the effects of self-objectification in the context of social relationships among young adults. Participants were 235 undergraduates (55.7\% females). A three-step model was successfully tested: results showed that internalization of media standards is related to increased self-objectification $(\beta=.33, S E=.08, p=.01)$, which in turn is associated with authenticity, being high self-objectifiers less devoted to authentic living $(\beta=-.21, S E=.09, p=.01)$ and more self-alienated $(\beta=.14, S E=.08, p=.04)$ and dependent on others' influence $(\beta=.50, S E=.01, p=.01)$. The pattern of these relationships did not significantly vary across gender $\left(\chi^{2}=6.29 ; p=.18\right)$. Implications concerning the impact of self-objectification in the domain of social relationships are discussed.
\end{abstract}

Received 25 May 2015; Revised 3 May 2016; Accepted 4 May 2016

Keywords: authenticity, gender, mass media, self-objectification.

Feminist analyses have provided a social constructionist account of the female body, showing that in Western societies the female body is socially constructed as an object to be looked at and evaluated. The objectification theory (Fredrickson \& Roberts, 1997) argues that women often are regarded as objects by society, with the focus being placed on all or part of their bodies in a sexual context rather than on their abilities. When objectified, women are reduced to the status of "mere instruments" available for visual inspection, evaluation, and the pleasure of others (Bartky, 1990, p. 26). Through the pervasiveness of objectification experiences, women are socialized to internalize an observers' perspective upon their body. This process is called self-objectification and happens when women treat themselves as objects to be considered and evaluated based upon appearance (Fredrickson \& Roberts, 1997).

Mass media play a key role in promoting selfobjectification through the extensive sexualization of women's body and the separation of sexualized body parts from the rest of the female body. However, it is not just exposure to mass media per se that seems detrimental: the real problem comes when individuals internalize such sexually objectifying messages

Correspondence concerning this article should be addressed to Chiara Rollero. Faculty of Psychology. University eCampus. Via Isimbardi, 10. 22060. Novedrate (Co) (Italy).

E-mail: chiara.rollero@uniecampus.it
(Vandenbosch \& Eggermont, 2012). The internalization of the objectifying messages from the media causes women to self-objectify and guides the perception of their worth (Rollero, 2015; Vandenbosch \& Eggermont, 2012). Empirical research has largely demonstrated that internalization of media ideals has a direct impact on self-objectification processes (Karazsia, van Dulmen, Wong, \& Crowther, 2013; Moradi \& Huang, 2008).

Since the foundational work of Fredrickson and Roberts (1997), numerous studies have investigated the damaging psychological corollary of self-objectification. Correlational studies have found relationships between self-objectification and body shame, appearance anxiety, negative and depressive affect, and various forms of disordered eating (e.g. Miner-Rubino, Twenge, \& Fredrickson, 2002; Tiggeman \& Kuring, 2004). Experimental research has demonstrated that heightened self-objectification promotes body shame, appearance anxiety, and hinders task performances (for a review see Moradi \& Huang, 2008).

Although objectification theory is grounded in women's experiences, researchers have begun to investigate the applicability of this framework to explore men's experience as well (e.g., Johnson, McCreary, \& Mills, 2007; Rollero, 2013). Men seem to experience lower self-objectification than do women, but especially young male adults are becoming increasingly more concerned with their physical appearance (Moradi \& Huang, 2008; Weltzin et al., 2005). This may be due to 
the increasing tendency to objectify men's physiques in Western societies, which fosters body image concerns among men (Bully \& Elosua, 2011; Johnson et al., 2007). Consistent with the pattern of findings in female populations, internalization of media ideals increases self-objectification even in men (Vandenbosch \& Eggermont, 2014) and men's self-objectification is negatively correlated with self-esteem, positive mood and less disordered eating (Calogero, 2009; Rollero, 2013).

Surprisingly, to date empirical research has not focused on the effects of self-objectification in the context of social relationships, with few exceptions considering romantic relationships (e.g., Meltzer \& McNulty, 2014; Zurbriggen, Ramsey, \& Jaworski, 2011). Exploring how self-objectification can affect the way individuals behave in their social context could contribute to advance our knowledge on objectification processes. If the focus on one's own appearance interferes with time and attention dedicated to forming an authentic connection with a romantic partner (Zurbriggen et al., 2011), this might happen even in the other kinds of relationships people are involved in. Individuals may experience disconnection from their feelings, values, aspirations, as significant portions of their conscious attention "can often be usurped by concerns related to real or imagined, present or anticipated, surveyors of their physical appearance" (Fredrickson \& Roberts, 1997, p. 180). In sum, driving the attention to physical appearance, self-objectification might affect authenticity in social relationships.

\section{The conceptualization of authenticity}

The notion of authenticity has long been a prominent concern for philosophers and social thinkers. In modern times, authenticity emerged as an essential concept within a number psychological perspectives, including existential (Yalom, 1980), humanistic (Maslow, 1973; Rogers, 1961), psychodynamic (Horney, 1950), social (Kernis \& Goldman, 2006), and positive psychology (Sheldon \& Lyubomirsky, 2004). As Maslow stated, "authenticity is the reduction of phoniness toward the zero point" (Maslow, 1973, p. 183). According to Rogers (1961), authenticity can be conceived as the sense of empowerment and freedom to behave in a way which is an expression of deeply held principles, aims, and feelings, rather than the consequence of external expectations. Authentic individuals would experience coherence between their thoughts, feelings, and behaviors (Rogers, 1961).

Based on this Roger's (1961) theoretical foundation, a recent approach considers that, to be authentic, one's actions should be in line with the personal values, beliefs and motivations of which one is aware (Wood, Linley, Maltby, Baliousis, \& Joseph, 2008). This approach conceptualizes authenticity as involving three components. The first aspect of authenticity is selfalienation and refers to the experience of feeling out of touch with the true self. Self-alienation is conceived as the degree of incongruence between the individual's experience of physiological states, emotions, and cognitions and the way these experiences are represented in cognitive awareness (Wood et al., 2008). The second component is named authentic living and refers to the congruence between behavior and experience as consciously perceived. Authentic living implies being true to oneself and living in accordance with one's values and beliefs (Wood et al., 2008). The third component is defined as accepting external influence and is related to the internalization of the views of other people. It involves the extent to which one accepts the influence of others and allows them to control his/her own actions (Wood et al., 2008). This model provides a comprehensive consideration of the concept of authenticity, as it encompasses both internal dimensions, i.e. the experience of being in touch and congruent with the true self, and environmental and social dimensions, i.e., the influence of others and the necessity to conform or not to their expectations. As Schmid (2005) argued, since people are basically socially beings, self-alienation and authentic living can not be conceived without considering the role played by the social environment individuals live in. Consistently, literature has demonstrated that authentic behavior is a more property of social interactions than of persons: the experience of authenticity has been found to be strongest within social environments promoting self-disclosure and mutual social support and acceptance (Robinson, Lopez, Ramos, \& Nartova-Bochaver, 2012).

Over the past decade, the interest in the consequences and correlates of authenticity has significantly increased (Wickham, 2013). In general, research has largely shown that authenticity is fundamental for many positive outcomes. It is associated with greater life satisfaction and well-being, higher levels of selfesteem, and positive affect (Kifer, Heller, Perunovic, \& Galinsky, 2013; Theran, 2010; Wood et al., 2008) and predicts more adaptive coping styles (Kernis \& Goldman, 2006). Moreover, authenticity decreases negative affect, perceived stress, anxiety, and verbal defensiveness (Lakey, Kernis, Heppner, \& Lance, 2008; Wood et al., 2008).

\section{Current study}

The aim for this research project was to bring the study of objectification processes into the context of social relationships, to understand the association between self-objectification and authenticity among young adults. Specifically, we were interested in examining whether self-objectification affects the extent to which individuals 
feel self-alienated, experience authentic living and accept others' influence.

Based on prior research, we expected that internalization of appearance ideals would be related to valuing one's appearance over competence, i.e., selfobjectification (Karazsia et al., 2013; Moradi \& Huang, 2008), which in turn would decrease each dimension of authenticity in social relationships. By testing this model, we aimed to overcome two limitations of prior research by (a) extending the study of the damaging consequences of self-objectification to the context of social relationships; and (b) exploring whether the hypothesized relationships differ between men and women. As Moradi and Huang (2008) pointed out, empirical research is necessary to evaluate, rather than assume, construct equivalence for men and women.

\section{Method}

\section{Participants and procedure}

Participants were 235 Italian undergraduates (55.7\% females) attending the first year of the Faculty of Political Sciences at the University of Turin, a city of about 900000 inhabitants in the north west of Italy. Their mean age was 20.90 years (range: 19-27 years, $S D=1.86$; men's mean age: $20.71, S D=2.18$, women's mean age: $21.05, S D=1.55, T=-1.40$, n.s.). The ethnic composition of the sample was completely homogeneous, being all participants Italian. They were recruited in two classrooms during a break and were given a copy of a self-reported questionnaire. Participants were told that their answers would have been treated in a strict confidence and the anonymity of all of them would have been secured. Informed consent was obtained by the students. No fulfilment of course requirements was given in exchange for their participation. The rejection rate was $3.8 \%$.

\section{Measures}

Data were gathered by a self-reported questionnaire which took about 15 min to be filled in. Participants were asked to complete the following scales:

\section{Internalization of media standards}

The 9-item Internalization-General subscale of the Sociocultural Attitudes Towards Appearance Questionnaire-3 (SATAQ-3; Rollero, 2015; Thompson et al., 2004) was used. Items are rated on a 5-point Likert scale ( 1 = definitely disagree, $5=$ definitely agree $)$. $(\alpha=.92)$. Sample of items include "I would like my body to look like the models who appear in magazines".

\section{Self-objectification Questionnaire}

Following Noll and Fredrickson's (1998) procedure, participants were asked to rank a list of body attributes in ascending order of how important each is to their physical self-concept, from that which has the most impact (rank $=1$ ) to least impact (rank = 12). Twelve body attributes were listed: six that were appearance based (i.e., physical attractiveness, coloring, weight) and six that were competence based (i.e., muscular strength, stamina, health). Scores were computed by summing the ranks for the appearance and competence attributes separately, then computing a difference score. Scores range from -36 to 36 , with higher scores reflecting a greater emphasis on appearance, which is interpreted as greater self- objectification (Noll \& Fredrickson, 1998). In the present study, a strong negative correlation was demonstrated between appearance and competence rankings, indicating good reliability $(r=-.91$, $p=.02)$.

\section{Authenticity Scale}

This is a 12-item instrument that measures authenticity (Wood et al., 2008; for the Italian version see Rollero, Spotti, \& De Piccoli, 2013). It contains three subscales, one of which is a positive indicator and two of which are negative indicators of authenticity. The positive indicator subscale refers to authentic living (AL) (4 items, i.e. "I think it is better to be yourself, than to be popular", $\alpha=.74$.). The negative indicator subscales refer to accepting external influence (AEI) (4 items, i.e. "I am strongly influenced by the opinions of others", $\alpha=.83$ ) and self-alienation (SA) (4 items, i.e. "I feel as if I don't know myself very well", $\alpha=.66)$. Items are rated on a 7-point scale ranging from 1 (does not describe me at all) to 7 (describes me very well).

\section{Results}

Descriptive statistics are reported in Table 1. Before testing the hypothesized model, T-tests were performed to assess gender differences concerning internalization of media standards, self-objectification, and the three components of authenticity. As presented in Table 2, no significant difference was observed.

The hypothesized relationships were tested with structural equation modelling (software Amos 4.0, Arbuckle \& Wothke, 1999) using the maximum likelihood method. As recommended (Bentler, 2007; Bollen \& Long, 1993), the model fit was tested by using different fit indexes to reduce the impact of the limits of each index: $\chi^{2}$, GFI (Goodness of Fit Index), Adjusted GFI, CFI (Comparative Fit Index), and RMSEA (Root Mean Square Error of Approximation). For GFI, Adjusted 
Table 1. Descriptive analyses and correlations of the studied variables

\begin{tabular}{|c|c|c|c|c|c|c|c|c|}
\hline & Min & Max & $M$ & $S D$ & Intern. & Self-Obj. & AL & AEI \\
\hline Internalization & 1 & 5 & 1.98 & .86 & & & & \\
\hline Self-objectification & -36 & 32 & -11.08 & 14.08 & $.34^{* *}$ & & & \\
\hline Authentic Living & 2.75 & 7 & 5.69 & .94 & -.12 & $-.21^{*}$ & & \\
\hline Accepting Ext. Influence & 1 & 7 & 2.74 & 1.26 & $.25^{* *}$ & $.19^{*}$ & $-.33^{* *}$ & \\
\hline Self-alienation & 1 & 6.75 & 3.24 & 1.22 & $.19^{*}$ & $.14^{*}$ & $-.19 *$ & $.44^{* *}$ \\
\hline
\end{tabular}

$$
{ }^{*} p<.05 * * p<.01
$$

Table 2. Gender differences on the studied variables

\begin{tabular}{lcccc}
\hline & Men & Women & $T$ value & Sig \\
\hline & $M(S D)$ & $M(S D)$ & & \\
Internalization & $1.94(.82)$ & $2.01(.89)$ & -.61 & n.s. \\
Self-objectification & $-11.02(14.69)$ & $-11.12(13.62)$ & .05 & n.s. \\
Authentic Living & $5.73(.83)$ & $5.66(1.02)$ & .55 & n.s. \\
Accepting External & $2.67(1.24)$ & $2.80(1.28)$ & -.78 & n.s. \\
$\quad$ Influence & & & & \\
Self-alienation & $3.23(1.19)$ & $3.25(1.25)$ & -.14 & n.s. \\
\hline
\end{tabular}

GFI, and CFI values higher than 0.90 are considered satisfactory. As for RMSEA, values lower than 0.08 are indicative of model fit (Bentler, 2007).

The model tested proved satisfactory, according to all fit indexes, except $\chi^{2}: \chi^{2}(3, N=231)=11.81 ; p=.01$; $\mathrm{GFI}=.98$; Adjusted GFI = .95; CFI $=.98$, RMSEA $=.03$. Given that the significance of $\chi^{2}$ depends on the sample size, the model could be considered well fitting (Bentler, 2007). All the estimated parameters were significant. Figure 1 shows the validated model. As expected, internalization of media standards lead to increased selfobjectification $(\beta=.33, S E=.08, p=.00)$, which in turn strongly related to accepting external influence $(\beta=.50$, $S E=.01, p=.00)$ and self-alienation $(\beta=.14, S E=.08$, $p=.04)$ and decreased authentic living $(\beta=-.21, S E=.09$, $p=.00$ ). Following the theoretical conceptualization of authenticity (Wood et al., 2008), the error terms for the three subscales were correlated and results showed that the correlations between the dimensions of authenticity were significant. Specifically, authentic living was negatively correlated with both accepting external influence and self-alienation, whereas these two last dimensions were strongly positively related.

Finally, a multiple groups analysis assessed the moderating role of gender by testing whether the fit of the model, which assumes that the hypothesized relationships do not vary across gender and are thus constrained to be equal between men and women, differs significantly from the fit of a model that allows the relationships to vary between men and women (Byrne, 2010). Results revealed that the relationships did not significantly vary between genders, $\chi^{2}(4,231)=$ $6.29 ; p=.18^{1}$.

\section{Discussion}

The present research aimed to investigate the effects of self-objectification on authenticity in social relationships among male and female undergraduates. It was successfully tested a three-step process, which begins with the internalization of media standards. Such internalization raises the focus on appearance over competence, i.e. self-objectification, which in turn makes individuals less aware of their feelings and values, and more dependent on others' influence.

Two conclusions can be derived. First, selfobjectification has an impact on individuals' perception of authenticity in social relationships. Consistently with findings about romantic relationships (Zurbriggen et al., 2011), it is likely that high self-objectified undergraduates feel more self-alienated, as they experience higher disconnection from their physiological states, emotions, and cognitions. The objectification theory perspective posits that self-objectification leads women to separate themselves from their own bodily sensations, decreasing their sensitiveness to internal bodily states (Fredrickson \& Roberts, 1997). The present study represents a first attempt to investigate the effects of self-objectification on awareness of psychological states. Our results suggest that we are dealing with the same process: self-objectification, reflecting a focus on body appearance, diminishes individuals' awareness not only of their own internal bodily states, but also of their own feelings, needs, desires and values. As above seen, feeling in touch with the true self is an essential component of authenticity (Wood et al., 2008). Being unaware of their psychological states, high self-objectified individuals are also more sensitive to external influences and behave less authentically. Another possible explanation suggests that self-objectified subjects are so embedded in self-objectification processes, which deny their value as persons (Fredrickson \& Roberts, 1997),

${ }^{1}$ The full variance-covariance matrix of the analyses here presented is available from the author by request. 


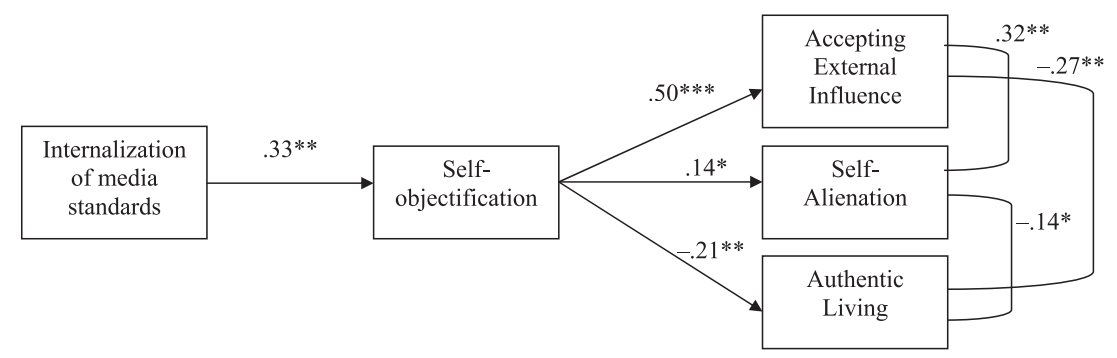

Figure 1. Path diagram and standardized regression weights.

${ }^{*} p<.05,{ }^{* *} p<.01,{ }^{* * *} p<.001$

that even if they are aware of their internal states, they believe that such states are unimportant, or at least less important than their appearance.

Second, the pattern of the above described relationships is similar across gender. Although previous literature has shown that men seem to experience lower self-objectification than do women (Moradi \& Huang, 2008; Weltzin et al., 2005) and it is a general consensus that body issues are more sensitive and problematic for girls than for boys (Balaguer, Atienza, \& Duda, 2012; Borges, Gaspar de Matos, \& Diniz, 2013), recent studies have demonstrated similar results across gender (Vandenbosch \& Eggermont, 2014). This may be due to the increasing cultural tendency to objectify men's bodies as well. Indeed, in contemporary Western societies men are similarly exposed to images of body type ideals and encouraged to adopt the ideal body valued by society (Daniel, Bridges, \& Martens, 2014). Our findings support the idea that these increasing depictions lead to the development of self-objectification processes even within male population. However, they deserve future attention, as the experience of self-objectification may maintain gender-specific characteristics, even if both genders are similarly socialized to internalize and observers' perspective upon their body.

Authenticity is recognized as a central component of the good life in philosophical thought and represents a key concept in psychology, as it is argued to serve as the foundation for a secure sense of high self-esteem that is resilient to external threats. Indeed, empirical research has largely demonstrated that authenticity plays a relevant role in enhancing or maintaining well-being (Davis, Hicks, Schlegel, Smith, \& Vess, 2015). For this reason, it is essential exploring processes that may compromise authenticity, such as self-objectification.

The current study extends our knowledge on selfobjectification processes. However, it presents some limitations. First, emotions were not considered. Theorists from the humanistic tradition suggest that emotions are central to authenticity because a feeling of authenticity signals to the individual that the self is integrated and organized (Sheldon, Ryan, Rawsthorne, \& Ilardi, 1997). Future research should integrate in research the assessment of emotions. Moreover, authenticity represents a complex construct: other instruments, such as the Authenticity Inventory (AI-3, Kernis \& Goldman, 2006), or qualitative data would enrich knowledge on this construct and associated psychological variables. Another limitation is that the current sample is comprised of young adult. Given that authenticity is considered to be a developmental construct (Maslow, 1962), the present results can not be generalized to adults in midlife or older adults. Finally, selecting only Caucasian subjects we did not examine the influence of culture, which is particularly relevant in reference to both self-objectification processes and authenticity as a value (Robinson et al., 2012). Further research should consider the key role played by culture.

\section{References}

Arbuckle J. L., \& Wothke W. (1999). Amos 4.0. Chicago, IL: Smallwaters.

Balaguer I., Atienza F. L., \& Duda J. L. (2012). Self-perceptions, self-worth and sport participation in adolescents. The Spanish Journal of Psychology, 15, 624-630. http:/ / dx.doi. org/10.5209/rev_SJOP.2012.v15.n2.38873

Bartky S. L. (1990). Femininity and domination: Studies in the phenomenology of oppression. New York, NY: Routledge.

Bentler P. M. (2007). On tests and indices for evaluating structural models. Personality and Individual Differences, 42, 825-829. http:/ /dx.doi.org/10.1016/j.paid.2006.09.024

Bollen K. A., \& Long J. S. (1993). Testing structural equation models. London, UK: Sage.

Borges A., Gaspar de Matos M., \& Diniz J. A. (2013). Body image and subjective well-being in Portuguese adolescents. The Spanish Journal of Psychology, 16. http:/ / dx.doi. org/10.1017/sjp.2013.24

Bully P., \& Elosua P. (2011). Changes in body dissatisfaction relative to gender and age: The modulating character of BMI. The Spanish Journal of Psychology, 14(1), 313-322. http:/ /dx.doi.org/10.5209/rev_SJOP.2011.v14.n1.28

Byrne B. B. (2010). Structural equation modeling using AMOS. Basic concepts, applications, and programming. New York, NY: Routledge. 
Calogero R. M. (2009). Objectification processes and disordered eating in British women and men. Journal of Health Psychology, 14, 394-402. http:/ / dx.doi. org/10.1177/1359105309102192

Daniel S., Bridges S. K., \& Martens M. P. (2014). The development and validation of the Male Assessment of Self-Objectification (MASO). Psychology of Men E Masculinity, 15(1), 78-89. http:/ /dx.doi.org/10.1037/a0031518

Davis W. E., Hicks J. A., Schlegel R. J., Smith C. M., \& Vess M. (2015). Authenticity and self-esteem across temporal horizons. The Journal of Positive Psychology, 10, 116-126. http:/ /dx.doi.org/10.1080/17439760.2014.910830

Fredrickson B. L., \& Roberts T. A. (1997). Objectification theory: Toward understanding women's lived experience and mental health risks. Psychology of Women Quarterly, 21, 173-206. http:/ / dx.doi.org/10.1111/j.1471-6402.1997. tb00108.x

Horney K. (1950). Neurosis and Human Growth. New York, NY: Norton.

Johnson P. J., McCreary D. R., \& Mills J. S. (2007). Effects of exposure to objectified male and female media images on men's psychological well-being. Psychology of Men $\mathcal{E}$ Masculinity, 8, 95-102. http:/ / dx.doi.org/10.1037/15249220.8.2.95

Karazsia B. T., van Dulmen M. H. M., Wong K., \& Crowther J. H. (2013). Thinking meta-theoretically about the role of internalization in the development of body dissatisfaction and body change behaviors. Body Image, 10, 433-441. http:/ /dx.doi.org/10.1016/ j.bodyim.2013.06.005

Kernis M. H., \& Goldman B. M. (2006). A multicomponent conceptualization of authenticity: Theory and research. Advances in experimental social psychology, 38, 283-357. http:/ /dx.doi.org/10.1016/S0065-2601(06)38006-9

Kifer Y., Heller D., Perunovic W. Q. E., \& Galinsky A. D. (2013). The good life of the powerful: The experience of power and authenticity enhances subjective well-being. Psychological Science, 24, 280-288. http:/ /dx.doi.org/ $10.1177 / 0956797612450891$

Lakey C. E., Kernis M. H., Heppner W. L., \& Lance C. E. (2008). Individual differences in authenticity and mindfulness as predictors of verbal defensiveness. Journal of Research in Personality, 42(1), 230-238. http:/ /dx.doi. org/10.1016/j.jrp.2007.05.002

Maslow A. H. (1962). Some basic propositions of a growth and self-actualization psychology. In A. Maslow, Toward a psychology of being, (pp. 177-200). Princeton, NJ: D Van Nostrand. http:/ /dx.doi.org/10.1037/10793-014

Maslow A. H. (1973). The farther reaches of human nature. Harmondworth, UK: Penguin Books.

Meltzer A. L., \& McNulty J. K. (2014). “Tell me I'm sexy... and otherwise valuable": Body valuation and relationship satisfaction. Personal Relationships, 21(1), 68-87. http:/ /dx. doi.org/10.1111/pere.12018

Miner-Rubino K., Twenge J. M., \& Fredrickson B. L. (2002). Trait self-objectification in women: Affective and personality correlates. Journal of Research in Personality, 36, 147-172. http:/ / dx.doi.org/10.1006/jrpe.2001.2343

Moradi B., \& Huang Y. P. (2008). Objectification theory and psychology of women: A decade of advances and future directions. Psychology of Women Quarterly, 32, 377-398. http:/ /dx.doi.org/10.1111/j.1471-6402.2008.00452.x

Noll S. M., \& Fredrickson B. L. (1998). A mediational model linking self-objectification, body shame, and disordered eating. Psychology of Women Quarterly, 22, 623-636. http:/ / dx.doi.org/10.1111/j.1471-6402.1998.tb00181.x

Robinson O. C., Lopez F. G., Ramos K., \& Nartova-Bochaver S. (2012). Authenticity, social context, and well-being in the United States, England, and Russia: A three country comparative analysis. Journal of Cross-Cultural Psychology, 44, 719-737. http://dx.doi.org/10.1177/0022022112465672

Rogers C. R. (1961). On becoming a person. New York, NY: Houghton Mifflin.

Rollero C. (2013). Men and women facing objectification: The effects of media models on well-being, self-esteem and ambivalent sexism. Revista de Psicologia Social, 28, 373-382. http://dx.doi.org/10.1174/021347413807719166

Rollero C. (2015). "I know you are not real": Salience of photo retouching reduces the negative effects of media exposure via internalization. Studia Psychologica, 57, 195-202.

Rollero C., Spotti F., \& De Piccoli N. (2013). L'oggettivazione attraverso gli spot pubblicitari: l'influenza dei media su umore e autostima. [Objectification in advertisements: The effects on mood and self-esteem]. Psicologia di Comunità, $X$, 65-72. http://dx.doi.org/10.3280/PSC2013-002008

Schmid P. F. (2005). Authenticity and alienation: Towards an understanding of the person beyond the categories of order and disorder. Person-Centred Psychopathology: A Positive Psychology of Mental Health, 75-90.

Sheldon K. M., \& Lyubomirsky S. (2004). Achieving sustainable new happiness: Prospects, practices, and prescriptions. In P. A. Linley \& S. Joseph (Eds.), Positive psychology in practice. Hoboken, NJ: John Wiley \& Sons, Inc. http:/ / dx.doi.org/10.1002/9780470939338.ch8

Sheldon K. M., Ryan R. M., Rawsthorne L. J., \& Ilardi B. (1997). Trait self and true self: Cross-role variation in the Big-Five personality traits and its relations with psychological authenticity and subjective well-being. Journal of Personality and Social Psychology, 73, 1380-1393. http:/ /dx.doi.org/10.1037/0022-3514.73.6.1380

Theran S. A. (2010). Authenticity with authority figures and peers: Girls' friendships, self-esteem, and depressive symptomatology. Journal of Social and Personal Relationships, 27, 519-534. http://dx.doi. org /10.1177/0265407510363429

Tiggemann M., \& Kuring J. K. (2004). The role of body objectification in disordered eating and depressed mood. British Journal of Clinical Psychology, 43, 299-311. http:/ / dx.doi.org/10.1348/0144665031752925

Vandenbosch L., \& Eggermont S. (2012). Understanding sexual objectification: A comprehensive approach toward media exposure and girls' internalization of beauty ideals, self-objectification, and body surveillance. Journal of Communication, 62, 869-887. http:/ /dx.doi. org/10.1111/j.1460-2466.2012.01667.x

Vandenbosch L., \& Eggermont S. (2014). The three-step process of self-objectification: Potential implications for adolescents' body consciousness during sexual activity. Body Image, 11(1), 77-80. http:/ /dx.doi.org/10.1016/j. bodyim.2013.10.005 
Weltzin T. E., Weisensel N., Franczyk D., Burnett K., Klitz C., \& Bean P. (2005). Eating disorders in men: Update. The Journal of Men's Health \& Gender, 2, 186-193. http:/ / dx.doi.org/10.1016/j.jmhg.2005.04.008

Wickham R. E. (2013). Perceived authenticity in romantic partners. Journal of Experimental Social Psychology, 49, 878-887. http:/ /dx.doi.org/10.1016/j.jesp.2013.04.001

Wood A. M., Linley P. A., Maltby J., Baliousis M., \& Joseph S. (2008). The authentic personality: A theoretical and empirical conceptualization and the development of the Authenticity Scale. Journal of Counseling Psychology, 55, 385-399. http://dx.doi.org/10.1037/ 0022-0167.55.3.385

Yalom I. D. (1980). Existential psychotherapy. New York, NY: Basic Books.

Zurbriggen E. L., Ramsey L. R., \& Jaworski B. K. (2011). Self-and partner-objectification in romantic relationships: Associations with media consumption and relationship satisfaction. Sex Roles, 64, 449-462. http:/ /dx.doi.org/ 10.1007/s11199-011-9933-4 